\title{
MAPPING OF FOREST FIRE BURNED SEVERITY USING THE SENTINEL DATASETS
}

\author{
Suresh Babu K V ${ }^{1 *}$, Arijit Roy ${ }^{1}$, Ridhika Aggarwal ${ }^{2}$ \\ ${ }^{1}$ Disaster management studies, Indian Institute of Remote Sensing, ISRO, Dehradun, India \\ sureshbabu.iiith@gmail.com, arijitroy@iirs.gov.in \\ ${ }^{2}$ United Nations University Institute for the Advanced Study of Sustainability, Tokyo, Japan - ridhika11@ gmail.com
}

Commission V, SS: Disaster Monitoring, Damage Assessment and Risk Reduction

KEY WORDS: Sentinel, Forest fire, NBR, dNBR, RBR

\begin{abstract}
:
Forest fires are frequent phenomena in Uttarakhand Himalayas especially in the months of April to May, causing major loss of valuable forest products and impact on humans through the emissions and therefore effects the climate change. The major forest fire was started on May 19, 2018 and spread in 10 districts out of 13 districts of Uttarakhand state till the fire was suppressed after May 30, 2018. The burned area mapping is essential for the forest officials to plan for mitigation measures and restoration activities after the fire season. In this study, sentinel 2A \& 2B satellite datasets were used to map burned severity over Uttarakhand districts. Differenced Normalized Burn Ratio (dNBR) and Relativized Burn Ratio (RBR) were calculated and compared with the active fire points. Results shows that both the dNBR and RBR are in good agreement with the actual occurence of forest fires.
\end{abstract}

\section{INTRODUCTION}

The burned area mapping is essential for the forest officials to plan for mitigation measures and restoration activities after the fire season. Rapid and accurately mapping of fire burn severity is an essential initiative to support fire management activities such as strategic planning, mitigation measures and monitoring restoration of vegetation (Garcia and Caselles, 1991; Key and Benson, 1999; Michalek et al., 2000; Key and Benson, 2006; Parks et al., 2014). In the management of forests, it is necessary to analyze the impact of fire on the ecosystem. Burn severity can be defined as the degree of change in the vegetation and soil constituents due to the fire (Miller and Thode, 2007). Burn severity is an important parameter for predicting the vegetation structure and the regrowth restoration (Johnstone and Chapin, 2006; Macdonald et al., 2007). It is very difficult to map burn severity using traditional methods, especially in the case where terrain has complex topography and inaccessible areas. Currently there is a wide range of satellite based products from medium (30 $\mathrm{m})$ to high $(10 \mathrm{~m})$ spatial resolution that makes it possible to accurately map the burnt areas from regional to local levels. However, the increase in spatial resolution results in a decrease in temporal resolution and vice versa, which results in small burnt areas being left out. Studies carried out by several researchers across the world suggests that, burn severity mapping is more effective when the ratio, that combining near infrared and shortwave infrared of the electromagnetic spectrum because the burnt area show higher reflectance than the green vegetation in Short Wave Infra-red Region (SWIR) (Garcia and Caselles, 1991; Key and Benson, 1999; Parks et al., 2014). Burn severity mapping with high spatial resolution has been carried out with
Landsat series satellite imagery (Chuvieco and Congalton, 1998; Michalek et al., 2000) and the 'LISS-3' sensor of the IRS Indian satellite occasionally (Chuvieco and Congalton, 1998). Recently, Optical satellites of medium spatial resolution satellites such as Landsat 8 OLI (30m), IRS P6 AWIFS (56m) have been using across the world to map burnt areas (Garcia and Caselles, 1991; Key and Benson, 2006). In general, burn severity is most effective when the spectral ratio that combines both the NIR and SWIR bands and successful if applied to the satellite images acquired before and after the fire event (Garcia and Caselles, 1991; Key and Benson, 2006; Parks et al., 2014). In most of the studies, Normalized Burn Ratio (NBR) has been calculated from the NIR and SWIR bands and dNBR (differenced NBR) has been used for the mapping of burn severity. Relativized Burn Ratio (RBR) was proposed as an alternative to dNBR and showed the improvement than dNBR (Parks et al., 2014). In this study, dNBR and Relativized Burn Ratio (RBR) have been used for generating the burn severity and compared the results for the sentinel datasets.

In this study, sentinel 2A \& 2B satellite datasets were used to map burned severity over the Pauri Garhwal and Tehri Garhwal districts of Uttarakhand, India. Both the Sentinel 2 satellite and Landsat 8 data are freely available for download, however, the sentine2 satellite data has higher spatial resolution $(10 \mathrm{~m}, 20 \mathrm{~m})$ than Landsat 8 OLI datasets $(30 \mathrm{~m})$ and also the revisiting period of combined Sentinel $2 \mathrm{~A}$ and $2 \mathrm{~B}$ is 5 days when it comes to Landsat 8 of 16 days. Therefore, the Sentinel 2A and 2B satellite datasets were used to generate the burn severity map in this study.

\footnotetext{
* Corresponding author
} 


\section{STUDY AREA AND DATASETS}

The study area chosen as the Pauri and Tehri Garhwal districts of Uttarakhand state, which was covered in Sentinel 2A and 2B on the nearest dates of both the pre and post fire event i.e. 11 May, 2018 and 20 May 2018 of major fire episode.

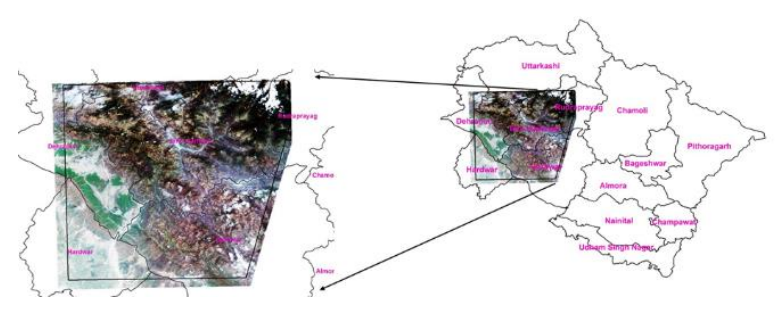

Figure 1. Study area

Sentinel 2 mission provide two satellites Sentinel $2 \mathrm{~A}$ and Sentinel 2B, as part of the joint program of EC (European Commission) and ESA (European Space Agency) and it has wide-swath, high spatial resolution $(10 \mathrm{~m}, 20 \mathrm{~m}$ and $60 \mathrm{~m})$ and multi spectral instrument (MSI), with 13 spectral bands from visible, NIR to SWIR (Sentinel website). The temporal resolution of a combination of sentinel $2 \mathrm{~A}$ and $2 \mathrm{~B}$ is 5 days at the equator and the datasets are useful for a wide range of applications especially in forestry and agriculture (Malenovský et al., 2012). The Sentinel 2A data on 15 May, 2018 (Pre fire event) and Sentinel 2 B data on 30 May, 2018 (Post fire event) over the study area, were downloaded from the Copernicus Open Access Hub.

Moderate Resolution Imaging Spectroradiometer (MODIS) Active fire hotspot data (MCD14) during the entire fire episode i.e. 19, May 2018 to 30, May 2018 were downloaded from the Fire Information for Resource Management System (FIRMS) website. The MCD14 data are actively burning locations at the time of satellite overpass and is in a point shapefile format with a spatial resolution of $1 \mathrm{~km}$. SUOMI NPP Visible Infrared Imaging Radiometer Suite (VIIRS) product (VNP14IMGTDL_NRT) has been providing information on the fire occurrence across the world on a daily scale with a spatial resolution of $375 \mathrm{~m}$ and these data can be downloaded from the FIRMS website. Both the MODIS and VIIRS data during the fire event overlaid on the burn severity map for the verification.

\section{METHODOLOGY}

Sentinel 2A and 2B satellite data sets of pre and post fire episode was downloaded and consists of 13 spectral bands of varying spatial resolutions from $10 \mathrm{~m}$ to $60 \mathrm{~m}$. The spectral bands were preprocessed to get the geometric corrected TOA reflectance bands. In this study, Bands 3, 8 and B12 were used to map the severity of burnt area. The Bands 3 and 8 are having $10 \mathrm{~m}$ spatial resolution, therefore these two bands were resampled into $20 \mathrm{~m}$ to match with the spatial resolution of band 12. Fig 1 shows the methodology flow to generate the burn severity map.

After resampling the Bands 3 and 8 to $20 \mathrm{~m}$, Normalized Burn Ratio (NBR) for the pre and post fire event were calculated. The NBR has been used to highlight the burnt areas, and is calculated from the NIR and SWIR bands, in case of sentinel, bands 8 and 12 were used (Key and Benson, 1999). Cloud mask has been used to remove the cloud pixels in the bands and NBR is calculated by using the equation 1 for sentinel $2 \mathrm{~A}$ and $2 \mathrm{~B}$ satellites.

$$
N B R=\frac{(\text { Band } 8-\text { Band } 12)}{(\text { Band } 8+\text { Band } 12)}
$$

Generally, NBR values are ranging from -1 to +1 . Healthy vegetation has very high reflectance in NIR region, where as the burnt areas show low reflectance. In contrast, burnt areas show higher reflectance and healthy vegetation show lower in SWIR region. Therefore, the higher NBR value indicates healthy vegetation and lower value for burned areas.

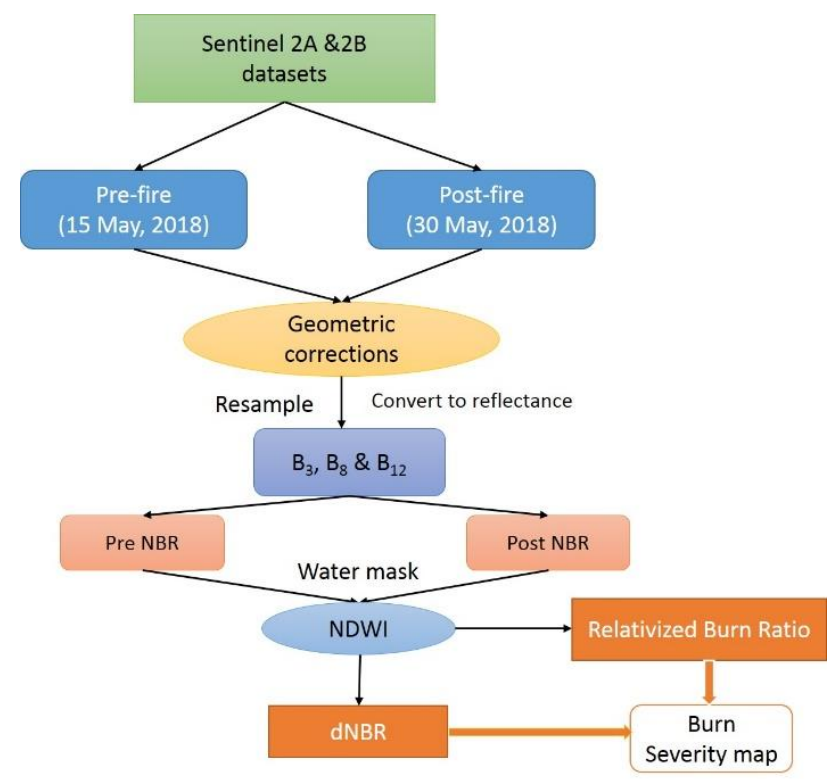

Figure 2. Methodology flow chart shows the generation of burn severity map

Water bodies in the image can show similar spectral reflectance as burnt areas, therefore, water pixels mask out in both the pre and post fire season. The Normalized Difference Water Index (NDWI) was used, to highlight the water body pixels (McFeeters, 1996).

$$
N D W I=\frac{(\text { Green }-N I R)}{(\text { Green }+N I R)}
$$

$$
N D W I_{\text {Sentinel }}=\frac{\left(B_{3}-B_{8}\right)}{\left(B_{3}+B_{8}\right)}
$$

NDWI was calculated for both the pre and post fire events by using equation (3). NDWI has been used to mask out the water pixels in the images.

NBR difference (dNBR) has been used by several authors to calculate the burned areas and burn severity (Wagtendonk et al., 2004; Cocke et al., 2005; Kokaly et al., 2006). The dNBR can be calculated from the NBR of pre and post fire events (Eq 4).

$d N B R=N B R_{\text {pre fire }}-N B R_{\text {post fire }}$ 
Relativized Burn Ratio (RBR) (Parks et al., 2014) is the ratio of dNBR to pre fire NBR adjustment and can be calculated by using the equation (5).

$$
R B R=\frac{d N B R}{\left(N B R_{\text {prefire }}+1.001\right)}
$$

In the denominator of $\mathrm{Eq}(5), 1.001$ is added to ensure that the denominator will never reach to zero (Parks et al., 2014).

\section{RESULTS AND DISCUSSION}

The resultant dNBR map was multiplied by a scale factor 1000 to categorize the fire severity levels. United States Geological Survey (USGS) proposed 7 interpretation levels based on the dNBR value (un-spider.org) and is shown in Table 1 and Burn severity map was generated by reclassifying the dNBR map on the basis of Table 1 .

\begin{tabular}{|l|l|l|}
\hline S. No. & Severity Level & dNBR range \\
\hline 1 & Enhanced Regrowth, High & -500 to -251 \\
2 & Enhanced Regrowth, Low & -250 to -101 \\
4 & Unburned & -100 to 99 \\
5 & Low Severity & 100 to 269 \\
6 & Moderate-Low Severity & 270 to 439 \\
7 & High Severity & 440 to 659 \\
\hline
\end{tabular}

Table 1. Burn severity levels (USGS)

A Field-based composite burn index was used to compare the dNBR ratios in some of the studies (Warner et al., 2017; Fraser et al., 2017). Several researchers across the world have used the satellite derived active fire points as a proxy for the actual occurrence of fires (Chuvieco et al., 2008; Adab et al., 2013; KV et al., 2016). Active fire points were taken as a proxy for the ground fire points as it is very difficult to cover and take the ground fire points data in the study area due to the hilly and rugged terrain (Babu et al., $2016 \mathrm{a}, \mathrm{b}$ ). Active fire hotspot product MODIS TEERRA and AQUA thermal anomaly product (MCD14) and VIIRS product (VNP14IMGTDL) during the fire event were downloaded over the study area from the Fire Information for Resource Management System (FIRMS) website (https://firms.modaps.eosdis.nasa.gov/). These are the actively burning fires during the time of satellite overpass. Active fire points are overlaid on the burn severity map to check the accuracy of the burn severity map. Fig 3 shows the Burn severity map over the study area. In the burn severity map, it was assumed that fires fell in low to high severity levels were categorized as burnt class and the rest of them are un-burnt. Number of fire points fell in the burnt and unburnt classes were extracted and Fig 4 shows the number of fire points fell in these two classes and it was evident that the maximum percentage $(81.5 \%)$ fires fell in burnt class.

Relativized Burn Ratio (RBR) map was generated by using the equation (5) and if the value is greater than 0.27 then the class is burnt otherwise un-burnt (Parks et al., 2014). The same fire points were used for the accuracy of RBR and Fig 5 shows the RBR image overlaid with fire points. The percentage of fires fell in burnt class is around $83.08 \%$, i.e. increase in accuracy as compared with the dNBR. This is due to the fact that value of dNBR is small when the forest areas covered with low vegetation because of change between the pre and post fire NBR will be small for these areas (Escuin et al., 2008; Parks et al., 2014). The RBR can determine the burn severity of low vegetation covers also. Finally, it was cleared from the above discussion that, Relativized burn ratio show higher accuracy than the difference Normalized Burn Ratio.

Thus, sentinel 2 satellite datasets will be useful for the mapping of burn severity rapidly as compared with the Landsat satellite datasets with improved spatial resolution. The temporal resolution of combined Sentinel $2 \mathrm{~A}$ and $2 \mathrm{~B}$ datasets is 5 days, therefore the burn severity map can be generated within the short span of time after the fire incidents.

\section{CONCLUSION}

In this study, sentinel 2A and 2B satellite datasets have been used to generate the burn severity map of Uttarakhand districts, India. Sentinel 2A datasets were downloaded for the pre fire event and sentinel 2B for post fire event so that the burn severity map was generated immediately after the event happened. Both the sentinel datasets were cloud masked and then applied Normalized Difference Water Index (NDWI) for water mask before calculating the burn severity as the burnt areas show similar reflectance as water bodies. In this study, difference Normalized Burn Ratio (dNBR) and Relativized Burn Ratio (RBR) were calculated and compared based on the number of active fire incidents (MCD14) of that event. The results were showing that RBR shown a better accuracy than dNBR because the RBR can determine the burn severity of low vegetation covered areas. Thus, the sentinel satellite datasets are useful to generate burn severity maps in quick time as compared with the Landsat satellite datasets due to the high temporal resolution and spatial resolution. 


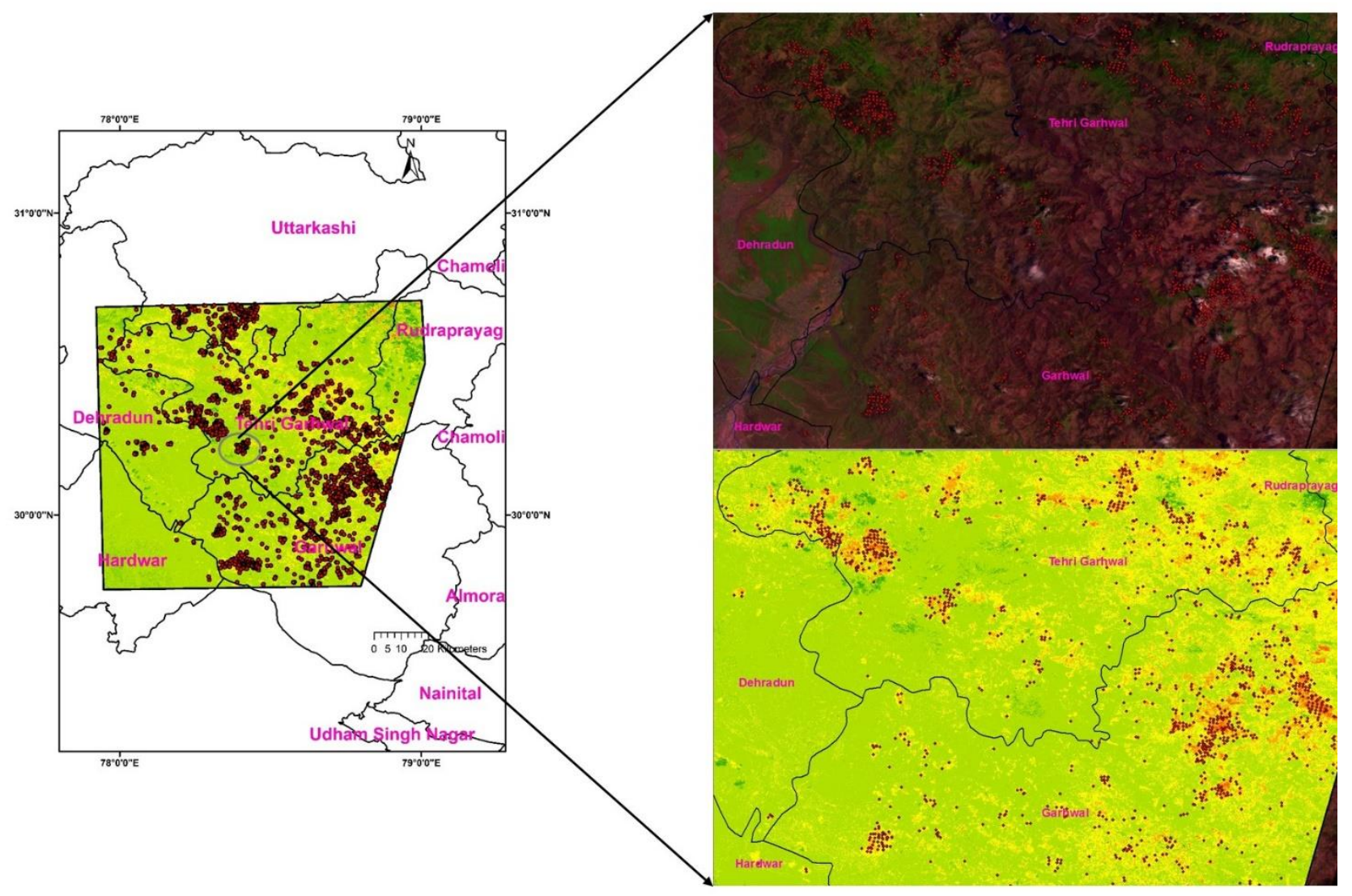

Figure 3. Burn severity map and zoomed extent shows the active fire hotspots overlaid on the various severity levels.

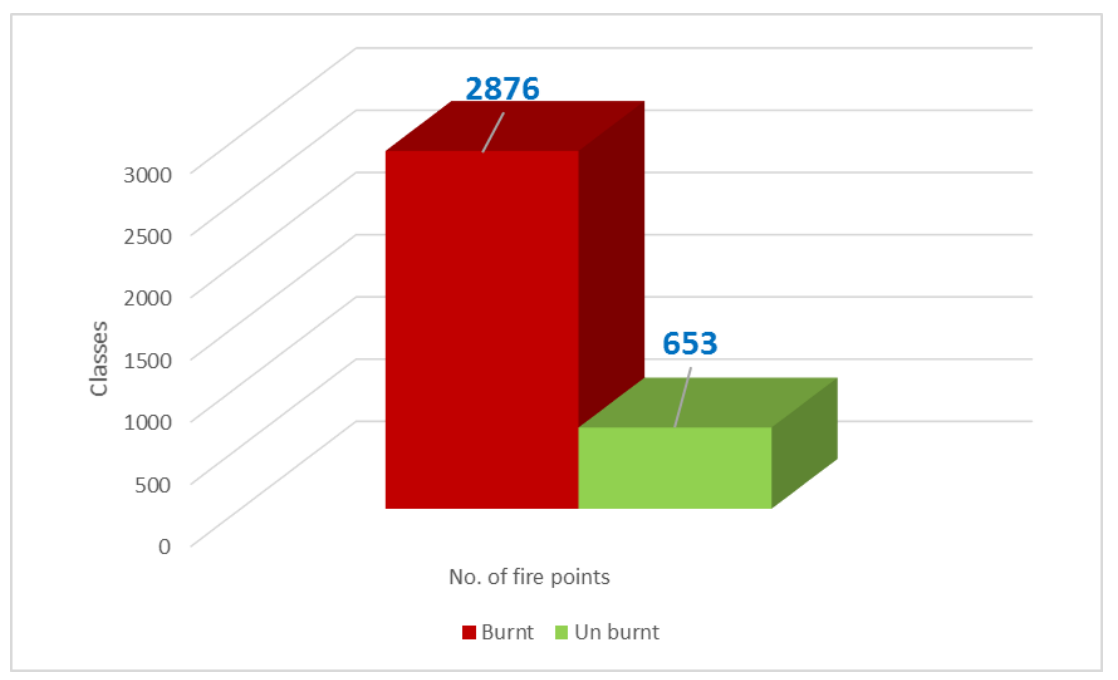

Figure 4. Number of fires in burnt classes of dNBR 


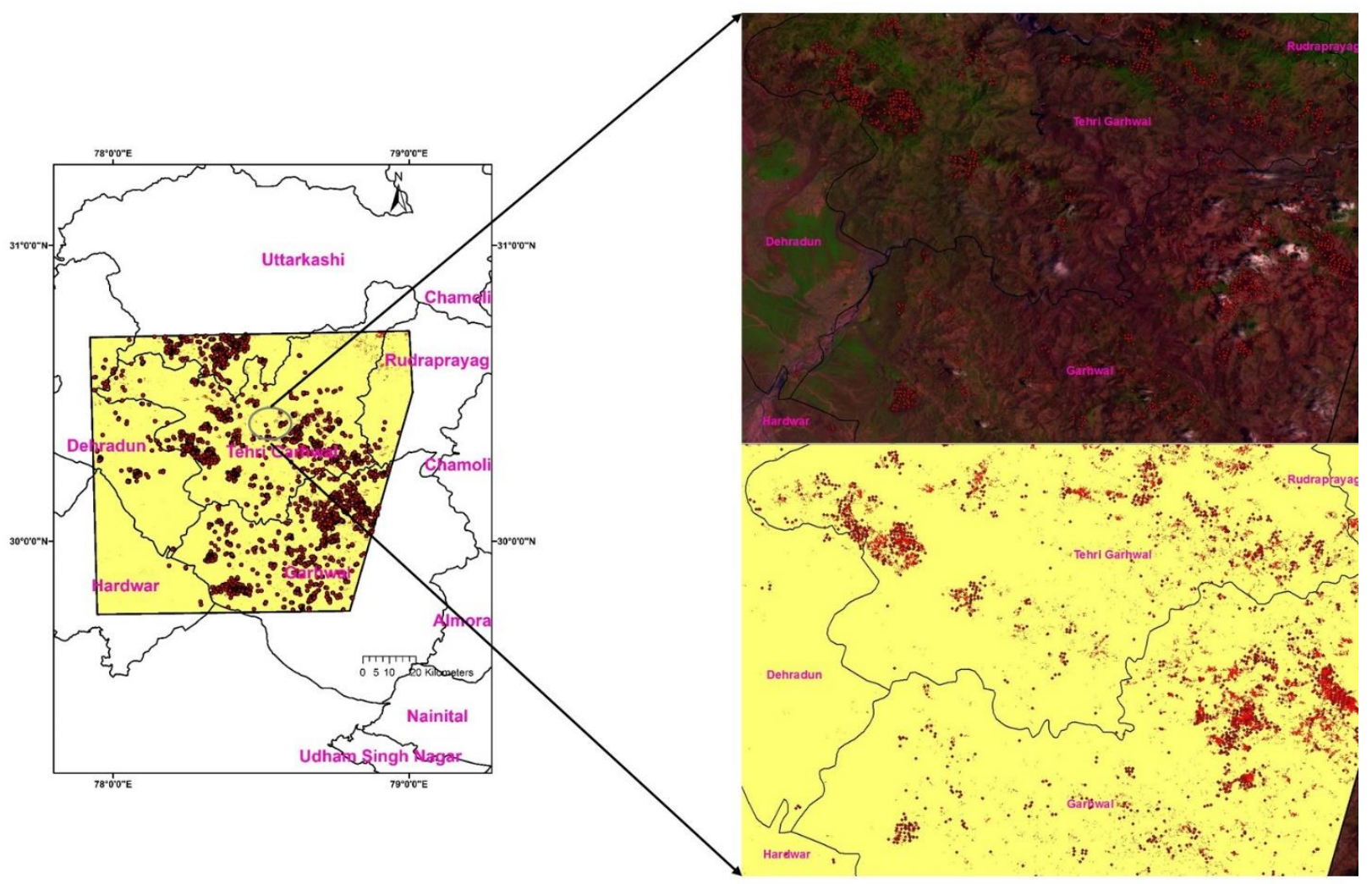

Figure 5. Relativized Burn Ratio map and zoomed extent shows the active fire hotspots overlaid

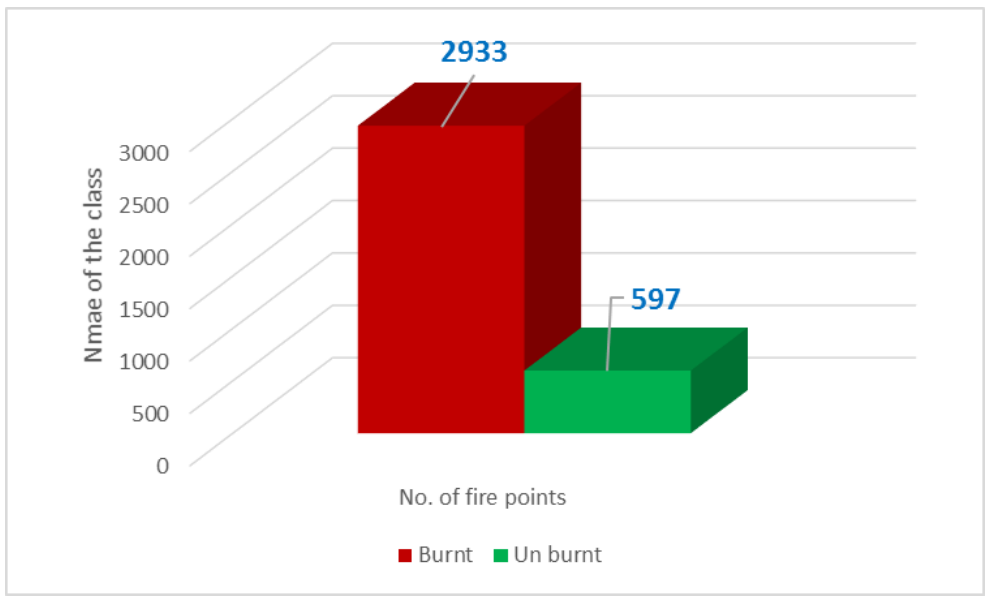

Figure 6. Number of fires in burnt classes of RBR

\section{ACKNOWLEDGEMENTS}

First author is grateful to Department of Science and Technology (DST), New Delhi, for awarding INSPIRE fellowship. Authors would be thankful to Director IIRS, Dr. Prakash Chauhan for their encouragement. Authors also acknowledge Prof. K S Rajan,
Head, Lab for Spatial Informatics, IIIT, Hyderabad for their suggestions and support throughout research. The authors acknowledge the use of data products or imagery from the Land, Atmosphere Near real-time Capability for EOS (LANCE) system operated by the NASA/GSFC/Earth Science Data and Information System (ESDIS) with funding provided by NASA/HQ. 


\section{REFERENCES}

Adab, H., Kanniah, K.D. and Solaimani, K., 2013. Modeling forest fire risk in the northeast of Iran using remote sensing and GIS techniques. Natural hazards, 65(3), pp.1723-1743.

Babu KV, S., Roy, A. and Prasad, P.R., 2016. Forest fire risk modeling in Uttarakhand Himalaya using TERRA satellite datasets. European Journal of Remote Sensing, 49(1), pp.381395.

Babu, K.S., Roy, A. and Prasad, P.R., 2016, December. Developing the static fire danger index using geospatial technology. In Contemporary Computing and Informatics (IC3I), 2016 2nd International Conference on (pp. 558-563). IEEE.

Chuvieco, E. and Congalton, R.G., 1988. Mapping and inventory of forest fires from digital processing of TM data. Geocarto International, 3(4), pp.41-53.

Chuvieco, E., Giglio, L. and Justice, C., 2008. Global characterization of fire activity: toward defining fire regimes from Earth observation data. Global change biology, 14(7), pp.1488-1502.

Cocke, A.E., Fulé, P.Z. and Crouse, J.E., 2005. Comparison of burn severity assessments using Differenced Normalized Burn Ratio and ground data. International Journal of Wildland Fire, 14(2), pp.189-198.

Copernicus Open Access Hub:

https://scihub.copernicus.eu/dhus/\#/home, accessed on 20 May, 2018.

Escuin, S., Navarro, R. and Fernandez, P., 2008. Fire severity assessment by using NBR (Normalized Burn Ratio) and NDVI (Normalized Difference Vegetation Index) derived from LANDSAT TM/ETM images. International Journal of Remote Sensing, 29(4), pp.1053-1073.

FIRMS website:

https://firms.modaps.eosdis.nasa.gov/download/ accessed on 30 May, 2018.

Fraser, R.H., van der Sluijs, J. and Hall, R.J., 2017. Calibrating satellite-based indices of burn severity from UAV-derived metrics of a burned boreal forest in NWT, Canada. Remote Sensing, 9(3), p.279.

García, M.L. and Caselles, V., 1991. Mapping burns and natural reforestation using Thematic Mapper data. Geocarto International, 6(1), pp.31-37.

Johnstone, J.F. and Chapin, F.S., 2006. Effects of soil burn severity on post-fire tree recruitment in boreal forest. Ecosystems, 9(1), pp.14-31.

Key, C.H. and Benson, N.C., 1999, June. Measuring and remote sensing of burn severity. In Proceedings joint fire science conference and workshop (Vol. 2, p. 284). University of Idaho and International Association of Wildland Fire Moscow, ID.

Key, C.H. and Benson, N.C., 2006. Landscape assessment: ground measure of severity, the Composite Burn Index. Pages LA8-LA15 in DC Lutes, editor. FIREMON: Fire Effects
Monitoring and Inventory System. USDA Forest Service, Rocky Mountain Research Station, Fort Collins, Colorado, USA.

Kokaly, R.F., Rockwell, B.W., Haire, S.L. and King, T.V., 2007. Characterization of post-fire surface cover, soils, and burn severity at the Cerro Grande Fire, New Mexico, using hyperspectral and multispectral remote sensing. Remote Sensing of Environment, 106(3), pp.305-325.

KV, S.B. and Roy, A., 2016, May. Forest fire danger index based on modifying Nesterov Index, fuel, and anthropogenic activities using MODIS TERRA, AQUA and TRMM satellite datasets. In Land Surface and Cryosphere Remote Sensing III (Vol. 9877, p. 98771A). International Society for Optics and Photonics.

Macdonald, S.E., 2007. Effects of partial post-fire salvage harvesting on vegetation communities in the boreal mixedwood forest region of northeastern Alberta, Canada. Forest Ecology and Management, 239(1-3), pp.21-31.

McFeeters, S.K., 1996. The use of the Normalized Difference Water Index (NDWI) in the delineation of open water features. International journal of remote sensing, 17(7), pp.1425-1432.

Michalek, J.L., French, N.H.F., Kasischke, E.S., Johnson, R.D. and Colwell, J.E., 2000. Using Landsat TM data to estimate carbon release from burned biomass in an Alaskan spruce forest complex. International Journal of Remote Sensing, 21(2), pp.323-338.

Miller, J.D. and Thode, A.E., 2007. Quantifying burn severity in a heterogeneous landscape with a relative version of the delta Normalized Burn Ratio (dNBR). Remote Sensing of Environment, 109(1), pp.66-80.

Parks, S.A., Dillon, G.K. and Miller, C., 2014. A new metric for quantifying burn severity: the relativized burn ratio. Remote Sensing, 6(3), pp.1827-1844.

Sentinel website: https://sentinel.esa.int/web/sentinel/userguides/sentinel-2-msi/overview, accessed on 21, March, 2018.

Un-spider: http://un-spider.org/node/10959 accessed on 12, April 2018.

Van Wagtendonk, J.W., Root, R.R. and Key, C.H., 2004. Comparison of AVIRIS and Landsat ETM+ detection capabilities for burn severity. Remote Sensing of Environment, 92(3), pp.397-408.

Warner, T.A., Skowronski, N.S. and Gallagher, M.R., 2017. High spatial resolution burn severity mapping of the New Jersey Pine Barrens with WorldView-3 near-infrared and shortwave infrared imagery. International journal of remote sensing, 38(2), pp.598-616. 